Finance and Economics Discussion Series Divisions of Research \& Statistics and Monetary Affairs Federal Reserve Board, Washington, D.C.

\title{
Recent Trends in the Number and Size of Bank Branches: An Examination of Likely Determinants
}

\section{Timothy H. Hannan and Gerald A. Hanweck}

\author{
2008-02
}

NOTE: Staff working papers in the Finance and Economics Discussion Series (FEDS) are preliminary materials circulated to stimulate discussion and critical comment. The analysis and conclusions set forth are those of the authors and do not indicate concurrence by other members of the research staff or the Board of Governors. References in publications to the Finance and Economics Discussion Series (other than acknowledgement) should be cleared with the author(s) to protect the tentative character of these papers. 


\section{RECENT TRENDS IN THE NUMBER AND SIZE OF BANK BRANCHES: AN EXAMINATION OF LIKELY DETERMINANTS}

by

Timothy H. Hannan*

Gerald A. Hanweck**

October 15, 2007

JEL: G21, L10, R3

Key Words: Banks Branching Location

*Senior Economist, Federal Reserve Board.

** School of Management, George Mason University, and Visiting Scholar, FDIC

Division of Insurance and Research.

The views expressed herein are those of the authors and do not necessarily reflect the views of the Board of Governors of the Federal Reserve System, the Federal Deposit Insurance Corporation, or their staffs. We would like to thank Dean Amel, Tara Rice, and Robin Prager for helpful comments and Miranda Mei for excellent research assistance. 


\begin{abstract}
In this paper, we examine the role of market characteristics in explaining the much discussed phenomenon of growth in the number of banking institution branches over time, and the much less discussed phenomenon of decline in the size of the average branch. Using a panel data set that consists of over 2,000 markets observed from 1988 to 2004, we report a number of findings regarding the market characteristics that are associated with the number of branches (of both commercial banks and savings associations) in a market and the average employment size of those branches. We find that the number of market branches is positively associated with the rate of return that banks in the market are able to obtain on their interest-bearing assets, inversely related to state branching restrictions, inversely related to market concentration, and, in the case of urban markets, positively related to measures of traffic congestion. Several other findings are also reported.
\end{abstract}




\section{Recent Trends in the Number and Size of Bank Branches: An Examination of Likely Determinants}

\section{Introduction}

In many parts of the United States, it is hard not to notice the proliferation of bank branches. In Illinois, for example, the number of banking offices increased by about 66 percent between 1994 and 2006. ${ }^{1}$ For the nation as a whole, the number of offices of commercial banks increased by a less impressive but still noteworthy 27 percent during the same period. At first glance, this proliferation of bank branches may seem surprising, given the well documented proliferation of automated teller machines (ATMs) and the advent of on-line banking. One might think that ATMs and on-line banking would serve as substitutes for the services offered at bank branches, thus reducing their numbers over time. ${ }^{2}$ This, however, does not appear to have been the case, at least not to the degree necessary to overcome factors that, as we document below, are associated with an increase in branching.

Figure 1 depicts the 39 percent rise in the number of branches of commercial banks in the US that occurred between 1988 to 2006. As indicated, except for a brief stall in the early 1990s, the rise has been continual, and may even have picked up speed in recent years. Note also, however, that, because the number of branches of savings associations declined substantially during this period, the increase in the number of branches of both types of institution combined (also presented in figure 1) came to only 12 percent during the period. Thus, one of the reasons for the often noted substantial rise in the number of commercial bank branches appears to have been a substitution of commercial bank branches for the branches of savings associations, either

\footnotetext{
${ }^{1}$ See Rice and Davis (2007).

${ }^{2}$ For these reasons, Speigel, Gart, and Gart in 1996 predicted that banks would close significant numbers of branches in the future.
} 
through acquisitions or by some other process. Urban and rural areas appear to have experienced similar trends, with branch growth only somewhat slower in rural areas. ${ }^{3}$

Other factors likely played an important role over time in explaining this rise in the number of branches. Between 1988 and 2005, the population of the United States increased by 21 percent, while real disposable personal income rose by nearly 66 percent. ${ }^{4}$ Thus, population, and particularly real income, grew substantially faster than the rise in the number of branches (of both commercial banks and savings associations) over the period, and it is not unreasonable to expect that the increase in the demand for branch services associated with these trends would, all else equal, have had a substantial positive influence on the number of branches. Additional factors to be investigated in detail below may also have played an important role.

Another trend that is perhaps less apparent concerns the average size of bank branches, as measured by the number of employees per branch. Rough calculations using data from County Business Patterns suggest that in the average urban market, the number of employees per branch operated by commercial banks declined from about 20 employees in 1988 to 16 by 1994 and to a little over 13 by 2004. For savings associations in urban areas, the number of employees per branch declined slightly from about 13 in 1988 to about 12 in 2004 . Trends observed for rural markets appear to have been quite similar, except that the employment size in bank branches declined from a higher level of 22 employees per branch in 1988 to about 14 per branch in 2004, and the average employment size of savings association branches was somewhat smaller in rural markets than in urban areas. ${ }^{5}$ These trends over time suggest a possible connection between the

\footnotetext{
${ }^{3}$ The number of commercial bank branches increased by 43 percent in urban areas and 27 percent in rural areas over this period, while the number of branches of commercial banks and savings associations combined increased by 13 percent in urban areas and 10 percent in rural areas.

${ }^{4}$ Economic Report of the President, 2006, p.319.

${ }^{5}$ To avoid distortions that may come from counting employees in the home office, establishments with more than 100 employees are excluded from these calculations. Urban markets here and throughout the paper are defined as
} 
rapid proliferation of bank branches over the period and changes in the nature of branch operations that resulted in fewer employees per branch.

In this paper, we investigate the extent and potential determinants of both of these phenomenon - the proliferation of bank branches and the reduction in branch size as measured by employment—using an extensive data set that covers over 2,000 local markets for the period from 1988 to 2004. Employing panel data estimation with both market and year fixed effects, we report evidence consistent with several hypotheses regarding the determinants of these phenomena. In the case of the number of branches in a defined local market, we find that market population, market per capita income, state-specific bank deregulation, market concentration, the return obtainable from deposit funds, and (in the case of urban markets) traffic congestion are all associated with the extent of branching in plausible ways. These same market characteristics, however, are not found to explain much of the change in branch size, probably because the change in branch size over time reflects predominantly the impact of technical innovations that are not easily measured. We do find, however, that markets experiencing above average growth in the number of branches experienced greater than average declines in the average employment size of their branches and offer possible explanations.

The plan of the paper is as follows: Section 2 describes the literature relevant to bank branching, and section 3 discusses likely determinants of the number and size of branches (bank plus savings association). Section 4 presents the empirical model employed, while section 5 discusses data sources and variable measurement. Section 6 presents estimation results, and section 7 summarizes and concludes.

Metropolitan Statistical Areas, and rural markets are defined as labor market areas, which in most cases correspond to rural counties. Average bank branch employment size was calculated for 314 urban markets and 1844 rural markets for which data were available for each year. Because some defined markets lost representation of savings associations over the period, reported averages for savings associations are calculated for numbers of markets that declined over the period. 


\section{The Literature}

While no paper to our knowledge has examined the issue of how the size of branches has changed over time, a few studies have examined aspects of the relationship between the number of bank branches and its determinants.

Two of the papers, Avery, et.al. (1999) and Damar (2007), focus on the issue of how mergers are associated with subsequent changes in the number of branches in a market or, in the case of Avery, et al. (1999), in a zip code area. Both papers employ the number of branches per population as the measure of branch intensity. Avery, et al., using data from the years 1975 to 1995, find that mergers of institutions with branch networks that overlap within a zip code area are associated with a reduction in offices per capita in that area. However, they find no such effect for out-of-market mergers or for mergers among institutions operating in the same market but not in the same zip code. Numerous characteristics of zip code areas or markets, such as personal income in the area, area population, and measures of concentration, are employed to control for other factors that may influence changes in branches per population over time.

Using a similar methodology, Damar (2007) examines the relationship between bank consolidations and subsequent changes in bank branches per population in markets in Turkey over the "post-crisis period” from 2001 to 2003. In addition to bank consolidation variables, the study employs changes in market concentration (variously derived), changes in market population, and changes in market GDP for statistical control. The study finds that consolidations involving failed institutions frequently resulted in reductions in the number of branches per population, but those involving healthy institutions were associated with increases in branching in the case of concentrated markets. 
Focusing on the branching decisions of individual banks, Kim and Vale (2001) employ a data set of Norwegian banks that covers the period 1988-1995. They report evidence that banks act strategically in their branching decisions, taking into consideration the future responses of rival banks. Although not examined by the authors, this effect suggests that market structure may be important in explaining the extent of bank branching in markets, since market structure is generally recognized as quite relevant to the formation of conjectures regarding rival responses.

Finally, a recent study by Rice and Davis (2007) focuses on the history of branching in Illinois. Among other things, their study points to at least two factors that may influence the extent of branching. First, deregulation of previously existing branch restrictions, such as those that existed in Illinois, can result in a dramatic expansion in the number of branches. Second, in comparing growth in the number of branches in the largest 15 cities during the period 19952005, they report evidence of a negative relationship between market concentration and branch growth. We investigate the role of both of these factors in this study.

\section{Potential Determinants of the Number and Size of Bank Branches}

In what follows, we consider separately the likely determinants of the number of branches (bank plus savings association) in a market and the average size of branches in a market.

The number of market branches. We presume as a general proposition that banks seek more deposits in a market when the revenue obtained by investing the funds (adjusted for risk) exceeds the cost of obtaining those funds. More local deposits may be obtained either by offering higher deposit rates and/or by providing the depositor with more convenience by means of a larger branch network, and profit maximization requires that in equilibrium, subject to 
qualifications, the incremental cost of obtaining local deposits through rate setting and branching should equate. An important qualification concerns the response of competitors to changes in deposit rates vs. changes in branch network. Since our focus is only on the total number of branches in a market, we will be concerned only with whatever equilibrium results from these competitive interactions among market participants.

These considerations lead us to predict a number of relationships between observable time-varying characteristics of markets and the number of market branches. First, and perhaps most trivially, the number of branches should increase with the population of the market. Of course, it would be possible to accommodate an increase in population with the same number of branches, each handling more depositors. But an increase in population is likely to entail a disproportionate increase in depositor locations that are less fully served by the existing branch network, and at the margin, the establishment of new branches should be less costly and/or more effective than raising deposit rates as a means of attracting deposits from those depositor locations. Diseconomies of scale at the branch level and increases in travel costs resulting from an increase in population would be additional reasons for a positive relationship between population and the number of market branches.

To the extent that it is a proxy for the value placed on travel time to the branch, income per capita should be positively related to the number of branch locations offered by banks. Greater value placed on travel time by depositors would change the optimal mix of deposit rates and branch network in favor of the convenience of branch networks as a means of attracting deposit dollars. However, this effect may be tempered by the fact that people with higher incomes have more non-bank investment options available to them, thus reducing their demand for banking products below what they would otherwise be. 
Because deposits are sought by banks to obtain income from investing the funds, any exogenous increase in the return obtainable from those funds should induce banks to seek more deposits. This should in turn induce banks to offer higher deposit rates and offer depositors greater convenience through an expansion of branch networks. This potential determinant of branching has been argued to be quite important during isolated periods of extreme financial distress. Damar (2007) notes, for example, that in an era of high budget deficits and inflation that existed in Turkey in the 1990s, banks found it profitable to collect deposits from the public and invest them in government securities bearing high real interest rates. Consequently, Turkish banks during the period expanded their branch networks rapidly to levels that were ultimately unsustainable. In contrast, after the banking difficulties in the late 1980s and 1990s, the rate of branch growth in the United States slowed after the decline in bank earnings. For example, net new branch office formation, defined as new offices excluding those offices formed from headoffices of banks and thrifts that failed or merged, declined from 1990 to 1993, just after bank and thrift failures had reached their peak in 1989. The recovery in branch growth came in 1994 and continued thereafter. While it seems reasonable that the return obtainable with deposit dollars should influence branch decisions, obtaining an empirical proxy for it is problematic, as discussed in more detail below.

Market concentration has long been thought to play a role in determining the degree of nonprice competition, as reflected in the number of branches in the case of the banking industry. Conjectured competitive responses to price and service changes are central to arguments concerning this relationship. Presumably, as market concentration reaches some high level, banks begin to internalize the response of rivals in reaching their branching decisions, and a 
lower equilibrium number of branches might result. ${ }^{6}$ If, however, firms begin to internalize the effect of their pricing decisions on rivals at some lower level of concentration than the one at which they internalize the effects of their nonprice decisions, there might exist some intermediate range of concentration whereby increases in concentration result in an increase in nonprice competition (branching in the case of the banking firm). To these considerations we must add the likely effects of horizontal mergers. If an observed increase in concentration stems from a horizontal merger, then the number of market branches may decline simply because the resulting organization finds it profitable to close overlapping facilities.

An explicit measure of traffic congestion, which will be employed for an urban subsample of banking markets, has a much less ambiguous prediction. It should be positively associated with the number of bank branches in the urban area, for reasons that are fundamental to spatial economics. By increasing the depositor's travel cost of moving a unit of distance to a branch, an increase in traffic congestion implies an increase in the optimal number (and more loosely, should result in an increase in the actual number) of market branches.

Banking markets may also differ in the degree to which they experience in-migration of new depositors. If it were not for switching costs, whereby depositors become "locked in” once they establish a relationship with a bank, this would presumably make no difference to a bank's pricing and branching decisions. With switching costs an important factor, however, the longterm payoff of attracting a new depositor entering the market becomes greater, inducing banks to offer more attractive deposit rates and, conceivably, more branch locations in markets that experience greater in-migration of depositors. Indeed, since convenient branch locations may be more readily observable to the in-migrating new depositor than an attractive deposit rate, and

\footnotetext{
${ }^{6}$ This effect would be ameliorated, however, to the extent that banks with market power establish additional branches to deter market entry. See Cohen and Masseo (2007) for evidence of this type of strategic behavior in banking.
} 
since branches probably represent more of a long-term commitment than does an attractive deposit rate (which can be rescinded at any time), the phenomenon of in-migration may be more important to bank branching decision than it is to the more commonly studied pricing decision. ${ }^{7}$

Perhaps the most policy-relevant of the potential determinants of branching to be examined concerns state branching restrictions. The lifting of previously existing branching restrictions may account for an increase in branching, to the extent that profitable opportunities for additional branches existed before the lifting of restrictions and the to the extent that those restrictions reduced the overall number of branches to a level lower than what they would otherwise be.

The Size of Bank Branches. A listing of the likely market determinants of the size of bank branches is more problematic, since any change over time is likely to stem predominantly from technological changes, broadly defined. Such changes may result from new technology that makes for easier coordination of a larger number of smaller branches to service customers. Another technological change concerns the increasing use of ATMs. By substituting for expensive tellers, the positioning of ATMs at branch locations may have changed the economics of branch operations such that larger numbers of smaller branches becomes optimal. Even if no induced change in the number of branches occurs as a result of this change, the potential for ATMs to substitute for tellers should reduce the size of branches, as measured by the number of employees. The recognition by banks that customers can be attracted through the placing of very small branch operations in supermarkets can also be considered a technological change, broadly defined, and this phenomenon may be significant in accounting for the observed decrease in branch size over time.

\footnotetext{
${ }^{7}$ See Beggs and Klemperer (1992) and Klemperer (1995) for a detailed examination of the role of switching costs in the pricing decision.
} 
Because we cannot measure underlying technological change, we will not be able to account empirically for what we consider to be the primary reason for the observed change in branch size over time. We do note, however, that, to the extent the technological change at issue is embodied disproportionately in newly opened branches, then one might predict that any market characteristic noted above as influencing the number of branches would thereby influence the observed size of branches in the opposite direction (since the newer branches would presumably be the smaller ones). While the recent placements of smaller branches in supermarkets most closely fits this notion that the newer branches should be smaller, it is not clear that other types of change, such as technologically-induced improvements in the coordination of branch operations or the placement of automated teller machines in branches, are likely to be embodied disproportionately in new branches.

\section{The Empirical Model}

In specifying the relationship between the number of branches in a market and likely determinants, previous researchers have employed only a linear functional form, which, before dividing through by market population, may be in our case expressed as:

$$
\begin{aligned}
b_{m t}= & \alpha_{0} \text { pop }_{m t}+\alpha_{1} \text { pop }_{m t}^{2}+\alpha_{2} \text { assetrate }_{m t} * \text { pop }_{m t}+\alpha_{3} \text { hhi }_{m t} * \text { pop }_{m t}+\alpha_{4} \text { inmigrants }_{m t} \\
& +\alpha_{5} \text { dereg }_{m t} * \text { pop }_{m t}+\alpha_{6} \text { conjest }_{m t} * \text { pop }_{m t}
\end{aligned}
$$

where $b r_{m t}$ denotes the number of branches in market $m$ during year $t$; $p o p_{m t}$ denotes the population of market $m$ during year $t$; assetrate $_{m t}$ denotes the rate earned on interest-bearing assets in market $m$ during year $t$; $h h i_{m t}$ denotes the Herfindahl-Hirschman Index (defined as the sum of squared deposit shares of banks and savings associations) in market $m$ during year $t$; immigrants $_{m t}$ denotes the number of potential new customers that came into market $m$ during 
year $t$; dereg $_{m t}$ is a dummy variable receiving the value of one if during year $t$ market $m$ was in a state where intrastate branching was completely “deregulated,” and zero otherwise; and congest $_{m t}$ is a measure of the level of traffic congestion in market $m$ during year $t$.

Note that because of the fundamental relationship between the number of branches in a market and the size of the market, the square of $p o p_{m t}$ is introduced to allow for nonlinearity in this relationship. In this specification, explanatory variables are interacted with pop $_{m t}$ when it is clear that their effect on total branches in the market should depend on the size of that market.

Dividing (1) by pop $p_{m t}$ (and including appropriate error terms) yields the functional form most commonly used in previous examinations of the determinants of bank branching, which in our case is:

$$
\begin{aligned}
b_{m t} / \text { pop }_{m t}= & \alpha_{0}+\alpha_{1} \text { pop }_{m t}+\alpha_{2} \text { assetrate }_{m t}+\alpha_{3} h h i_{m t}+\alpha_{4} \text { inmigration }_{m t}+\alpha_{5} \text { dereg }_{m t} \\
& +\alpha_{6} \text { congest }_{m t}+u_{m}+v_{t}+\varepsilon_{m t}
\end{aligned}
$$

where inmigration ${ }_{m t}$ is defined as inmigrants $s_{m} /$ pop $_{m t}, u_{m}$ denotes a market-specific fixed effect, $v_{t}$ denotes a year-specific fixed effect, ${ }^{\varepsilon_{m t}}$ denotes an idiosyncratic error, and all other terms are as previously defined. This is the functional relationship used exclusively in the previous literature. $^{8}$ Below, we report results obtained with the use of this specification, as well as one in which market personal income substitutes for $p p_{m t}$ as a measure of market size.

We also employ at alternative multiplicative specification, which, after taking natural logs, yields:

$$
\begin{aligned}
\ln \left(b_{m t}\right)= & \beta_{0}+\beta_{1} \ln \left({ }_{1} \text { pop }_{m t}\right)+\beta_{2} \ln \left(\text { inc }_{m t} / \text { pop }_{m t}\right)+\beta_{3}\left(\text { assetrate }_{m t}\right)+\beta_{4} \ln \left(\text { hhi }_{m t}\right) \\
& +\beta_{5} \ln \left(\text { inmigration }_{m t}\right)+\beta_{6} \text { dereg }_{m t}+\beta_{7} \ln \left(\text { congest }_{m t}\right)+u_{m}+v_{t}+\varepsilon_{m t}
\end{aligned},
$$

where inc $c_{m t}$ denotes total personal income in market $m$ at year $t$ (in real terms), and all other terms are as previously defined. Inclusion of the term $\beta_{2} \ln \left(i n c_{m t} / p o p_{m t}\right)$ in (2) allows for a test

\footnotetext{
${ }^{8}$ See Avery, et. al. (1999) and Damar (2007).
} 
of the role played by real per capita income in inducing bank branching. A finding that $\beta_{1}=\beta_{2}$ would imply that it is change in real income in the market, whether it stems from a change in population or a change in income per capita, that influences bank branching.

As noted above, we also examine the determinants of branch size over time, using the same explanatory variables. In log form, this relationship may be expressed as:

$$
\begin{gathered}
\ln \left(\text { brsize }_{m t}\right)=\gamma_{0}+\gamma_{1} \ln \left({ }_{1} \text { pop }_{m t}\right)+\gamma_{2} \ln \left(\text { inc }_{m t} / \text { pop }_{m t}\right)+\gamma_{3}\left(\text { assetrate }_{m t}\right)+\gamma_{4} \ln \left(\text { hhi }_{m t}\right) \\
+\gamma_{5} \ln \left(\text { inmigration }_{m t}\right)+\gamma_{6} \text { dereg }_{m t}+\gamma_{7} \ln \left(\text { congest }_{m t}\right)+u_{m}+v_{t}+\varepsilon_{m t}
\end{gathered}
$$

where brsize $_{m t}$ denotes the average branch size in the market (to be measured in terms of employment), and all other terms are as previously defined.

\section{The Data}

Of the variables employed in the analysis, the number of branches, market population, market income, and the Herfindahl-Hirschman index (HHI) of concentration are commonly used in studies of bank behavior. Markets are defined as the collection of counties that make up metropolitan areas in the case of urban areas and by labor market areas (as defined by the Bureau of Labor Statistics) in the case of rural areas. ${ }^{9}$ The number of branches in these areas is defined as the total number of offices operated by banks and savings associations. This information was obtained from the FDIC's Summary of Deposits (SOD) and the Office of Thrift Supervision's Branch Office Survey (BOS). Annual information on county population and personal income were obtained from the Bureau of the Census, and values of the measure of market concentration were constructed from data on branch deposits obtained from the SOD and the BOS. To express income in real terms, market personal income is adjusted for changes in the consumer price

\footnotetext{
${ }^{9}$ For non-metropolitan areas, these are typically identical to counties but sometimes involve larger areas obtained by combining counties when 15 percent or more of the employed workers in one area commute to the other. See http:/www.bls.gov/lau/laugeo.htm\#geolma for a detailed description.
} 
index. The deregulation variable (dereg) is defined as a binary variable that receives the value of one if, during the year observed, the market is in a state (or predominantly in a state) that allowed full intrastate branching. The data employed to construct this variable were obtained form Kroszner and Strahan (1999), with updates by the authors.

We have argued that the rate that banks can earn with deposit dollars should influence the extent to which they seek to obtain deposit dollars through branching. The question arises as to whether that rate should be a marginal or an average rate. If it is the marginal rate that matters (implying, under some circumstances, separability between the asset and liability side of the bank), then it is generally presumed that this would be the same for all banks, as banks set rates according to some elastically supplied asset or liability obtainable in a market that is at least national in scope. ${ }^{10}$ In this case, the effect of this consideration would be reflected fully in the coefficients of the time dummies included in the analysis.

If it is the average rate that matters, however, then banks may differ cross-sectionally in terms of the impact that this consideration has on their branching decisions. To investigate this, we calculate an average rate observed for banks operating in a market (assetrate). This is obtained by calculating, for each bank, the ratio of interest income to the sum of interest bearing assets, using annual data from bank reports of condition and income. After eliminating likely outliers by dropping the largest and smallest one percent of observations for each year, these bank-specific rates were aggregated to the market level by constructing a market weighted average, using bank deposit shares as the weights. In other words, each bank-specific rate is multiplied by that bank's deposit share in the market, and this is summed across all banks in the market to obtain a rough estimate of the average rate obtainable with deposit funds on the part of

\footnotetext{
${ }^{10}$ See Klein (1971).
} 
banks that operate in the market. ${ }^{11}$ As noted above, we also report results obtained without the inclusion of this variable.

Measures of the extent of in-migration into a market are derived from the IRS's Countyto County Migration Data. These data are based on the year-to-year changes in the addresses shown on the population of returns from the IRS individual Master File system. From these data one can calculate the proportion of returns filed for addresses in the market that reported an address outside the market during the previous year (approximating the proportion of new households in the market) and the proportion of all exemptions claimed by current residents in the market that were claimed in these returns (approximating the proportion of new residents in the market). ${ }^{12}$

Estimates of the average size of branches in a market, measured in terms of number of employees, are calculated from data obtained from the US Census Bureau’s County Business Patterns on the number of establishments in each county operated by commercial banks and savings associations. These counts of the number of establishments are broken down by ranges of the number of employees: 1-4, 5-9, 10-19, 20-49, 50-99, etc. Under the assumption that banking establishments with more than 100 employees are heavily involved in non-retail or central-office functions, only establishments with less than 100 employees are counted. An estimate of the average employment size of branches in each market was obtained for each year by calculating a weighted average of the midpoints of the five employment categories under 100 employees, where the shares of establishments in each of the five categories serve as the weights.

\footnotetext{
${ }^{11}$ This does imply that the rate obtainable by a multimarket bank, say Bankamerica, from investments outside the market help determine the extent to which it branches inside the market. Since deposits raised in one local area can be used to fund projects in another, we do not think that this is an unreasonable assumption.

${ }^{12}$ Migration from one county to another county in the same defined market is excluded in these calculations. These data also allow calculation of the aggregate income of in-migrants, but this information was not collected prior to 1996.
} 
Perhaps the most unusual measure to be employed in this study concerns the extent to which traffic congestion exists in the market. Such a measure may be obtained from the detailed analyses reported annually by the Texas Transportation Institute for approximately 87 urban areas. The annual data reported extend as far back as 1982. When improvements are made in either the processes or the data used in congestion estimates, such changes result in revisions of all previous estimates so that true trends can be developed whenever possible. The annual measure of congestions that we employ in this study is the annual delay (in hours) per peak traveler in the urban area. For the urban areas covered in the data, this measure increased from an average of 16 hours in 1982 to 46 hours in $2002 .^{13}$

\section{The Results}

Econometric results are presented separately for the number of market branches and for the average size of branches in the market.

The number of market branches. We consider first the relationship between the extent of branching in markets and various market characteristics, as discussed above. Table 1 lists the definitions of all variable employed in the analysis, while tables 2 and 3 present econometric results. All reported estimations include both market and year fixed effects, and all allow for non-zero correlation of errors for observations of the same market over time- $-\mathrm{a}$ feature that results in higher standard errors (lower t-statistics) than would otherwise be obtained. All reported explanatory variables are lagged one year.

\footnotetext{
${ }^{13}$ Annual reports on these trends, and much more, may be found at http://mobility.tamu.edu/ums. For a detailed discussion of the methodology employed in calculating the congestion measure used, see http://mobility.tamu.edu/ums/report/methodology.stm
} 
Table 2 presents results of estimations obtained employing the log-linear functional form, as expressed by equation (2). The first column reports results obtained for all 318 urban markets for which data on all variables other than the congestion variable are available; the second reports results obtained using the 87 urban markets for which data on traffic congestion is available; and the final column reports results obtained using a sample of 1,891 rural markets for which data are available and that have at least two branches.

The positive and highly significant coefficients of $\ln \left(\right.$ pop $\left._{t-1}\right)$ indicate, not surprisingly, that as a market increases in population, more branches are established in the market. Coefficient magnitudes suggest that for urban markets, a 10 percent increase in market population, all else equal, is associated with a 7 percent increase in the number of bank and savings association branches, while in rural markets, this figure would be closer to 5 percent.

The positive and highly significant coefficients of $\ln \left(y_{t-1} / p^{\prime} p_{t-1}\right)$ indicates that, controlling for market population, the income of consumers in the market has a substantial positive effect on the number of market branches. Coefficient magnitudes suggest that a 10 percent increase in market real per capita income would increase the number of market branches by 6 percent in urban markets, but only 2 percent in rural markets. The coefficients of $\ln \left(p o p_{t-1}\right)$ and $\ln \left(y_{t-1} / p p_{t-1}\right)$ are not statistically different from each other in the case of urban markets, suggesting that in such markets, it is market income rather than population that can be considered the more relevant measure of market size in explaining the number of market branches. ${ }^{14}$ The coefficients of these two variables are statistically different from each other in the case of rural markets.

\footnotetext{
${ }^{14}$ With the same coefficient, these two terms may be added to obtain that coefficient multiplied by $\ln \left(y_{t}\right)$.
} 
As indicated by the positive and highly significant coefficients of dereg $_{t-1}$ in all three regressions, state adoption of unrestricted statewide branching authority has had a substantial impact on the extent of branching. Coefficient magnitudes suggest that such authority is associated with about a 10 percent increase in the number of branches in urban markets and about a 5 percent increase in the number of branches in rural markets. These results are consistent with results reported by Rice and Davis (2007) for the state of Illinois, which experienced a virtual explosion in the number of branches after deregulation of its previously quite restrictive policies on bank branching.

The coefficients of $\ln \left(\right.$ assetrate $\left._{t-1}\right)$ are also positive and highly significant in all three regressions, suggesting that more remunerative opportunities to invest deposit funds are associated with more subsequent branches in the market. Coefficient magnitudes suggest that over time, a 10 percent increase in the rate earned on interest bearing assets is associated with a 3 percent increase in the number of branches in urban markets and a 1 percent increase in the number of branches in rural market markets. As noted above, this phenomenon of asset returns driving branching decisions has shown itself to be quite important during certain periods of perverse financial conditions. As also noted above, inclusion of this variable is not appropriate if it is the marginal, rather than the average, return obtainable with deposit funds that influences bank branching decisions. Estimations that exclude this variable yield coefficients of the other variables in the analysis that are virtually the same as those reported here. To conserve space, those results are not presented but are available from the authors upon request.

The coefficients of $\ln \left(h h i_{t-1}\right)$ are negative and highly significant in all three regressions, suggesting that high levels of market concentration are associated with lower levels of branching, all else equal. As noted above, conjectures regarding rival responses to deposit pricing and 
branching decisions are likely to play a major role in accounting for any observed relationship between market concentration and branching. The negative coefficients reported are consistent with the hypothesis that the greater recognized interdependence of branching decisions, as concentration increases, causes banking organizations to be less aggressive in establishing branches. The range at which this phenomenon is most likely to be relevant should entail higher levels of concentration, and it is interesting to note that the absolute value of this coefficient is greatest for rural markets, where levels of concentration are typically higher. The finding of negative coefficients of this variable may also reflect within-market mergers, which typically cause concentration to rise and often result in the subsequent closing of overlapping branches. This finding of a negative relationship between market concentration and branching has also been reported recently by Rice and Davis (2007).

The coefficients of $\ln \left(\right.$ inmigration $\left._{t-1}\right)$ vary in sign and are all statistically insignificant. Thus, we fail to find support in these regressions for the hypothesis that banks and savings associations are more aggressive in establishing branches in areas with a greater percentage of people who are new to the market.

Finally, and perhaps most interestingly, the coefficient of $\ln \left(\right.$ congest $\left._{t-1}\right)$ is positive and highly significant for the sample of 87 urban areas for which data on traffic congestion is available. The measure of congestion, defined as the annual delay (in hours) per peak traveler in the area, increased over time for almost all of these areas. With year fixed effects included, this result suggests that those urban areas that experienced above average increases in congestion exhibited above average increases in the number of branches. This result is consistent with basic predictions of spatial economics, which imply that as travel costs increase, the consumer will find closer locations relatively more desirable. In the case of the banking industry, this should 
induce banks to invest in more branches as a means of attracting depositors relative to other means of attracting them, such as by offering higher deposit rates.

It is conceivable, of course, that this finding reflects unmeasured changes in urban areas over time that are associated with both increased traffic congestion and increased branching. We note, however, that such market characteristics, if they exist, would have to be something other than market population or market personal income, both of which are controlled for in these regressions.

A couple of generalizations about the overall results presented in table 2 are worth noting. First, given that the first regression employs 318 markets, while the second employs 87, and the third employs 1,897, the similarity of coefficients (at least in sign) across these very diverse samples is quite striking, suggesting considerable robustness in underlying relationships. Second, with the exception of the coefficient of concentration, which, as noted above, is subject to special considerations, the absolute values of coefficients tend to be smaller in the case of rural markets. This may be due to the fact that many rural markets have very few branches. Because branches represent discrete investments, a given percentage increase in an explanatory variable may entail a smaller increase on average in the percent change in branches. This discreteness issue may also account for the smaller $\mathrm{R}^{2}$ statistic reported for rural markets. As noted above, all previous analyses of the extent of bank branching have employed a linear functional form in which the ratio of market branches to population serves as the dependent variable. Table 3 reports results that employ this and an equivalent functional form. Consider first the results of estimations reported in column (1) and (2), where branches per population $\left(b r_{t} / \mathrm{pop}_{t}\right)$ serves as the dependent variable, and the sample employed contain 318 and 87 urban markets, respectively. As may be seen from the derivation of equation (1') from 
equation (1) above, the constant term indicates the linear part of the estimated relationship between market population and the number of branches, while the coefficient of pop $p_{m t}$ in (1') may be seen from (1) to be that of the square of population. Thus, the negative and statistically significant coefficients of pop $_{t-1}$ reported in table 3 may be interpreted to imply that, all else equal, as population in a market increases, the resulting increment in the number of branches declines. This is roughly consistent with the results presented in table 2 , which indicate that the number of branches changes by a smaller percentage than the change in population, all else equal.

Results obtained for the remaining variables are equivalent to those reported using the log-linear functional form. The coefficients of dereg $_{t-1}$ are positive and highly significant, indicating again the importance of statewide branching restrictions as a determinant of the extent of branching in a market. The coefficients of assetrate $_{t-1}$ are also positive and highly significant, implying that the revenue obtainable from a dollar of deposits is positively related to the extent of branching in the market in the subsequent period. As in table 2, the coefficients of $h i_{t-1}$ are negative and statistically significant, while the coefficients of inmigration t- $1_{\text {are not statistically }}$ significant. As reported in column (2) for the reduced sample of 87 urban markets, the coefficient of congest $_{t-1}$ is positive and significant, as predicted, although in this case it is significant at only the 10 percent level.

As noted, results presented in table 2 suggest that market income is more highly correlated with branching in the market than is market population. Consequently, the regressions reported in columns (1) and (2) of table 3 are repeated in columns (3) and (4), with the difference that market income $\left(y_{t}\right)$ replaces population both in the denominator of the dependent variable and as an explanatory variable. As indicated from the corresponding $\mathrm{R}^{2}$ statistics, the use of 
market income appears to explain more of the overall within-market variation in branching. With one exception, the coefficients obtained using market income are equivalent qualitatively to those obtained using market population. The one exception is in the coefficient of congest $_{t-1}$, which, though positive, is not statistically significant.

The final two regressions presented in columns (5) and (6) report the two basic linear regressions using a sample of 1,897 rural markets that contain at least two branches. As indicated, coefficients are qualitatively similar to those reported for urban markets, except that the coefficients of inmigration $_{t-1}$ in these regressions are negative and statistically significant, in contrast to what one would expect if the rate of inflow of new potential depositors causes banking organizations to establish more branches per unit of population or of market income. Given the small size of most rural markets, this may simply reflect the many cases in which inmigration serves to increase the population or total income of the market (thus increasing the denominator of the dependent variables), but not sufficiently to justify investment in another branch.

The Size of Bank Branches. It is more problematic to trace the factors that have influenced the decline over time in the average size of bank branches, as measured by the number of employees that work in them. The reason is that, as discussed above, these changes in all likelihood occurred as a result of various types of technological innovations, which are quite difficult to measure. It will be instructive, nonetheless, to see how changes in branch size are associated with changes in the number of branches in markets. To this end, table 4 presents the results of four different regressions in which two different measures of branch intensiveness within markets, $b r_{t} / p o p_{t}$ and $b r_{t} / i n c_{t}$, are regressed on the average employment size of market branches, $b_{r s i z e}$, for both urban and rural markets, with both market and year fixed effects. It is 
important to note that no attempt is made here to assert causation. But changes in the number of market branches and the size of market branches are undoubtedly part of the same underlying process, and it is instructive to document any association that may stem from that process.

As indicated in table 4, all coefficients of brsize $_{t}$ are negative and statistically significant. Since year fixed effects are included, these detrended results suggest that those markets that experienced greater growth in branches per population or branches per real income over time also experienced greater reductions in the average size of their branches. A possible reason for this is that the labor saving impact of technological change is greater in the case of newer branches than older ones. It might also reflect the possibility that with fewer employees needed to handle the operations of a branch, a larger number of branches become desirable.

From this observed association, it is reasonable to question whether the market characteristics associated with the extent of branching, as documented in tables 2 and 3, are also associated, in the opposite direction, with the size of market branches. To investigate this, the regressions reported in table 2 were re-estimated using $\ln \left(\right.$ brsize $\left._{t}\right)$ as the dependent variable. While coefficient signs do tend to be the opposite of those reported in table 2, most, particularly in the case of urban markets, are not statistically significant. The major exception in the case of urban markets are the coefficient of assetrate $_{t-1}$, which is negative and statistically significant in the case of the full sample, and the coefficients of inmigration in $_{t-1}$, which are positive and statistically significant. The results obtained for rural markets provide some support for the hypothesis that market characteristics relate to branch size in the direction opposite to their relationship with market branching, since the coefficient of the lagged deregulation variable $\left(\right.$ dereg $\left._{t-1}\right)$ is negative and significant, while the coefficient of lagged concentration $\left(h h i_{t-1}\right)$ is positive and significant, the opposite to that reported in table 3. 


\section{Conclusion}

In this paper, we examine the much discussed phenomenon of growth in the number of bank branches over time, as well as the much less discussed phenomenon of decline in the size of the average bank branch, as measured by branch employment. Our primary goal has been to outline the market characteristics associated with both of these phenomena, as well as to present what we can determine about the relationship between the two.

In addition to more commonly used data sources, we bring to these questions sources of data not typically seen in studies of the banking industry. These include data from the US Census's County Business Patterns to obtain information on the number and employment distribution of banking “establishments” by market area, data from the Internal Revenue Service's County-to-County Migration Data to calculate rates of in-migration by market, and data reported by the Texas Transportation Institute on trends in traffic congestion in major urban areas.

Using a panel data set that consists of over 2,000 markets observed from 1988 to 2004 and an estimation procedure that includes both market and year fixed effects, we report a number of findings regarding the market characteristics that are associated with the number of branches in a market and the average employment size of those branches. We also report evidence regarding the detrended relationship between the number of market branches and average employment by branch.

In terms of determinants (or correlates) of the number of branches in the market, we first note that much of the frequently noted sharp increase in the number of bank branches in the US in recent years appears to result from the substitution of commercial bank branches for the 
branches of savings associations. To address additional factors, we estimate the relationship between market or state characteristics and the number of market branches of commercial banks and savings associations together. We report the following findings: (1) Using either market total income or market population as a measure of market size, the number of branches in a market increases, but less than proportionately, with market size. (2) Total personal income in the market appears to be much more strongly correlated with the number of market branches over time than is total population. In the case of urban markets, this is supported formally by failure to reject the hypothesis that, using a multiplicative functional form, the coefficients of the log of population and the log of income per capita are the same. (3) The rate that banks in a market are able to obtain on their interest-bearing assets is positively associated with the number of branches that they deploy in the market, all else equal. (4) Deregulation of state branching restrictions to allow full intrastate branching had a major positive effect on the number of market branches, all else equal. (5) As suggested in earlier studies, measures of market concentration are significantly negatively associated with the number of market branches over time, all else equal. (6) Urban areas that experienced above average increases in traffic congestion over time, all else equal, experienced above average increases in the number of bank branches—a result consistent with the predictions of basic spatial economics but perhaps reflecting other phenomena as well. (7) No consistent evidence of a relationship between migration into a market and the number of market branches over time is observed after controlling for other relevant factors.

In comparing the trend in the number of bank branches in individual markets with the trend in the average size of market branches, as measured by employment, we find that markets that experienced above average increases in the number of bank branches also experienced above 
average reductions in the average size of their branches. This may result because the labor saving impact of technological change is greater in the case of newer branches than older ones, implying that markets that establish more new branches thereby exhibit greater reductions in their average size. It might also reflect the possibility that with fewer employees needed to handle the operations of a branch, a larger number of branches becomes desirable.

Probably because changes in branch size over time reflect the impact of technological innovations that are difficult to measure, the same market characteristics that are associated strongly with the number of branches are not found to explain as much of the change in branch size. While the results obtained for rural markets tend to provide some support for the hypothesis that market characteristics relate to branch size in the direction opposite to their relationship with the number of branches, most reported coefficients in the case of urban markets are not statistically significant. 


\section{References}

Avery, Robert B., Raphael W. Bostic, Paul S. Calem, and Glenn B. Canner. "Consolidation and bank branching patterns,” Journal of Banking and Finance 23 (2-4) (1999).

Beggs, Allen, and Paul Klemperer. "Multi-Period Competition with Switching Costs,” Econometrica 60 (3) (May 1992), pp. 651-666.

Cohen, Andrew, and Michael Mazzeo. "Investment Strategies and Market Structure: An Empirical Analysis of Bank Branching Decisions,” Working Paper, Federal Reserve Board, 2007.

Damar, H. Evren. “Does Post-Crisis Restructuring Decrease the Availability of Banking Services? The Case of Turkey,” Journal of Banking and Finance (forthcoming).

Kim, M., and B Vale. "Non-price Strategic Behavior: The Case of Bank Branches.” International Journal of Industrial Organization, 19(10), (2000), pp. 1583-1602.

Klein, M. A. “A Theory of the Banking Firm,” Journal of Money, Credit and Banking 3, (1971) pp. 261-275. 
Klemperer , Paul. “Competition when Consumers have Switching Costs: An Overview with Applications to Industrial Organizations, Macroeconomics, and International Trade,” Review of Economic Studies, 62 (1995), 515-539.

Kroszner, Randall S., and Philip E. Strahan. "What Drives Deregulation? Economics and the Politics of the Relaxation of Bank Branching Restrictions,” The Quarterly Review of Economics, November 1999, pp. 1437-1467.

Rice, Tara, and Erin Davis. “The branch banking boom in Illinois: A byproduct of restrictive branching laws,” Chicago Fed Letter, Federal Reserve Bank of Chicago, No. 238, May 2007. 
Table 1

Variable Definitions

\begin{tabular}{|c|c|}
\hline$b r_{t}$ & $\begin{array}{l}\text { Total number of branches of commercial banks and savings } \\
\text { associations in the market in year } t\end{array}$ \\
\hline pop $_{t}$ & Total population of the market in year $\mathrm{t}$ \\
\hline$y_{t}$ & Total real income of the market in year $\mathrm{t}$ \\
\hline dereg $_{t}$ & $\begin{array}{l}\text { A dummy variable that equals one if, in year } t \text {, the market was in a } \\
\text { state (or predominantly in a state) in which full, statewide intrastate } \\
\text { branching was allowed, and zero otherwise }\end{array}$ \\
\hline assetrate $_{t}$ & $\begin{array}{l}\text { The average rate earned on interest bearing assets of banking } \\
\text { institutions in the market at year } t\end{array}$ \\
\hline$h h i_{t}$ & $\begin{array}{l}\text { The Herfindahl-Hirschman Index (calculated as the sum of squared } \\
\text { deposit market shares) for all commercial banks and thrift institutions } \\
\text { operating in the market at year t }\end{array}$ \\
\hline inmigration $_{t}$ & $\begin{array}{l}\text { An estimate of the proportion of the population in year } t \text { that had } \\
\text { moved to the market during the previous year (see text) }\end{array}$ \\
\hline congest $_{t}$ & $\begin{array}{l}\text { A measure of urban congestion, defined as the annual delay (in } \\
\text { hours) per peak traveler in the area at year } t\end{array}$ \\
\hline brsize $_{t}$ & $\begin{array}{l}\text { The average number of employees per branch of banks and savings } \\
\text { associations in the market at year t, excluding those offices with } \\
\text { more than } 100 \text { employees (see text) }\end{array}$ \\
\hline
\end{tabular}


Table 2

\begin{tabular}{|c|c|c|c|}
\hline \multicolumn{4}{|c|}{$\begin{array}{l}\text { The Relationship Between the Number of Branches in a Market } \\
\text { and Market Characteristics, with Year and Market Fixed Effects } \\
\text { (Log-Linear Functional Form) }\end{array}$} \\
\hline & \multicolumn{2}{|c|}{ Urban markets } & \multirow{2}{*}{$\begin{array}{c}\text { Rural markets } \\
\text { (3) }\end{array}$} \\
\hline & (1) & (2) & \\
\hline Dep var.: & $\ln \left(b r_{t}\right)$ & $\ln \left(b r_{t}\right)$ & $\ln \left(b r_{t}\right)$ \\
\hline constant & $\begin{array}{r}-1.49 \\
(-1.43)\end{array}$ & $\begin{array}{c}-1.99 \\
(-1.09)\end{array}$ & $\frac{-.26}{(-.60)}$ \\
\hline $\ln \left(\right.$ pop $\left._{t-1}\right)$ & $.70^{* *}$ & $.71^{* *}$ & $.47 * *$ \\
\hline & $(8.95)$ & $(5.75)$ & $(11.34)$ \\
\hline $\ln \left(y_{t-1} / p^{\prime} p_{t-1}\right)$ & $.60^{* *}$ & $.58^{* *}$ & $.18^{* *}$ \\
\hline & $(5.05)$ & $(3.22)$ & $(6.25)$ \\
\hline dereg $_{t-1}$ & $.087 * *$ & $.11^{* *}$ & $.047 * *$ \\
\hline & (6.69) & $\left(4.18^{*}\right)$ & $(9.08)$ \\
\hline $\ln \left(\right.$ assetrate $\left._{t-1}\right)$ & $.32 * *$ & $.31 * *$ & $.11 * *$ \\
\hline & $(7.06)$ & $(4.34)$ & $(5.24)$ \\
\hline $\ln \left(h h i_{t-1}\right)$ & $-.12^{* *}$ & $-.088^{* *}$ & $-.20^{* *}$ \\
\hline & $(-6.59)$ & $(-3.57)$ & $(-11.81)$ \\
\hline In(inmigration $\left.{ }_{t-1}\right)$ & .029 & -.006 & -.014 \\
\hline & $(1.34)$ & $(-.21)$ & $(-1.27)$ \\
\hline $\ln \left(\right.$ congest $\left._{t-1}\right)$ & & $.082^{* *}$ & \\
\hline & & (3.38) & \\
\hline $\mathrm{R}^{2}$ (within) & .43 & .52 & .19 \\
\hline No. of observations & 5,083 & 1,387 & 29,881 \\
\hline No. of markets & 318 & 87 & 1,897 \\
\hline
\end{tabular}

Note: All regressions include market and year fixed effects and account for correlated errors within markets. t-statistics are reported in parentheses, and the symbols,$+ *$, and $* *$ denote statistical significance at the 10, 5, and 1 percent levels, respectively. 
Table 3

The Relationship Between the Number of Branches in a Market and Market Characteristics, with Year and Market Fixed Effects (Linear Functional Forms)

\begin{tabular}{|c|c|c|c|c|c|c|}
\hline & \multicolumn{4}{|c|}{ Urban Markets } & \multicolumn{2}{|c|}{ Rural Markets } \\
\hline & (1) & (2) & (3) & (4) & (5) & (6) \\
\hline Dep var.: & $b r_{t} / p o p_{t}$ & $b r_{t} / p^{\prime} p_{t}$ & $b r_{t} / y_{t}$ & $b r_{t} / y_{t}$ & $b r_{t} / p^{\prime} p_{t}$ & $b r_{t} / y_{t}$ \\
\hline constant & .00024 & .00021 & .0018 & .0014 & .00057 & .0049 \\
\hline & $(12.43)$ & $(6.05)$ & (15.03) & (8.28) & $(29.22)$ & (32.43) \\
\hline$p_{p o p} t-1$ & $-.54 \mathrm{E}-12 * *$ & $-.29 \mathrm{E}-12+$ & & & $-.31 \mathrm{E}-10 * *$ & \\
\hline & $(-3.55)$ & $(-1.76)$ & & & $(-7.85)$ & \\
\hline $\mathrm{y}_{\mathrm{t}-1}$ & & & $-.56 \mathrm{E}-11 *$ & $-.24 \mathrm{E}-11$ & & $-.58 \mathrm{E}-9 * *$ \\
\hline & & & $(-1.95)$ & $(-.82)$ & & $(-4.43)$ \\
\hline dereg $_{t-1}$ & $.28 \mathrm{E}-4^{* *}$ & $.38 \mathrm{E}-4^{* *}$ & $.00016^{* *}$ & $.00018^{* *}$ & $.22 \mathrm{E}-4^{* *}$ & $.88 \mathrm{E}-4^{* *}$ \\
\hline & $(6.82)$ & $(5.20)$ & $(6.16)$ & $(4.42)$ & $(7.17)$ & (3.57) \\
\hline assetrate $_{t-1}$ & $.0011^{* *}$ & $.0011^{* *}$ & $.0064 * *$ & $.0061 * *$ & $.00091^{* *}$ & $.0060 * *$ \\
\hline & $(7.20)$ & $(4.71)$ & (5.93) & $(4.03)$ & (6.07) & $(4.32)$ \\
\hline$h h i_{t-1}$ & $-.14 \mathrm{E}-9 * *$ & $-.12 \mathrm{E}-9 *$ & $-.80 \mathrm{E}-9 *$ & $-.77 \mathrm{E}-9 *$ & $-.19 \mathrm{E}-9 * *$ & $-.16 \mathrm{E}-8 * *$ \\
\hline & $(-2.84)$ & $(-2.16)$ & $(-2.51)$ & $(-2.50)$ & $(-7.92)$ & $(-7.60)$ \\
\hline inmigration $_{t-1}$ & $.77 \mathrm{E}-4$ & $-.60 \mathrm{E}-7$ & -.00028 & -.00015 & $-.00020+$ & $-.0043 * *$ \\
\hline & $(1.54)$ & $(-.10)$ & $(-.84)$ & $(-.40)$ & $(-2.25)$ & $(-5.77)$ \\
\hline congest $_{t-1}$ & & $.38 \mathrm{E}-8+$ & & $.25 E-8$ & & \\
\hline & & $(1.71)$ & & $(.18)$ & & \\
\hline & & & & & & \\
\hline $\mathrm{R}^{2}$ (within) & .243 & .436 & .429 & .646 & .075 & .163 \\
\hline No. of observations & 5,083 & 1,387 & 5,083 & 1,387 & 29,881 & 29,881 \\
\hline No. of markets & 318 & 87 & 318 & 87 & 1.897 & 1,897 \\
\hline
\end{tabular}


Table 4

The Association Between the Number of Branches in a Market and the Average Size (measured by number of employees) of Branches in the Market

\begin{tabular}{|c|c|c|c|c|}
\hline & \multicolumn{2}{|c|}{ Urban markets } & \multicolumn{2}{|c|}{ Rural markets } \\
\hline & (1) & (2) & (5) & (6) \\
\hline Dep. var.: & $\mathrm{br}_{\mathrm{t}} / \mathrm{pop}_{\mathrm{t}}$ & $\mathrm{br}_{\mathrm{t}} / \mathrm{y}_{\mathrm{t}}$ & $\mathrm{br}_{\mathrm{t}} / \mathrm{pop}_{\mathrm{t}}$ & $\mathrm{br}_{\mathrm{t}} / \mathrm{y}_{\mathrm{t}}$ \\
\hline constant & $.39 E-3$ & .0028 & $.55 \mathrm{E}-3$ & .0049 \\
\hline & (103.45) & (110.23) & (251.37) & (244.47) \\
\hline brsize $_{t}$ & $-.37 \mathrm{E}-7 * *$ & $-.27 \mathrm{E}-4^{* *}$ & $-.15 \mathrm{E}-7^{* *}$ & $-.12 \mathrm{E}-4 * *$ \\
\hline & $(-19.06)$ & $(-20.34)$ & $(-17.30)$ & $(-15.83)$ \\
\hline $\mathrm{R}^{2}$-within & .169 & .423 & .035 & .146 \\
\hline No. of observations & 5,080 & 5,080 & 30,063 & 30,063 \\
\hline No. of markets & 318 & 318 & 1,901 & 1,901 \\
\hline
\end{tabular}

Note: All regressions include market and year fixed effects and account for correlated errors within markets. t-statistics are reported in parentheses, and the symbols,$+ *$, and $* *$ denote statistical significance at the 10 , 5 , and 1 percent levels, respectively. 
Table 5

\begin{tabular}{|c|c|c|c|}
\hline \multicolumn{4}{|c|}{$\begin{array}{l}\text { The Relationship Between the Average Employment per Branch in a Market } \\
\text { and Market Characteristics, with Year and Market Fixed Effects } \\
\text { (Log-Linear Functional Form) }\end{array}$} \\
\hline & \multicolumn{2}{|c|}{ Urban markets } & \multirow{2}{*}{$\begin{array}{c}\text { Rural markets } \\
\text { (3) }\end{array}$} \\
\hline & (1) & (2) & \\
\hline Dep var.: & $\ln \left(\right.$ brsize $\left._{t}\right)$ & $\ln \left(\right.$ brsize $\left._{t}\right)$ & $\ln \left(\right.$ brsize $\left._{t}\right)$ \\
\hline \multirow[t]{2}{*}{ constant } & 2.02 & 3.22 & 2.34 \\
\hline & $(2.07)$ & ( 2.04) & $(4.01)$ \\
\hline \multirow[t]{2}{*}{$\ln \left(\right.$ pop $\left._{t-1}\right)$} & .043 & -.019 & -.061 \\
\hline & $(.59)$ & $(-.18)$ & $(-1.18)$ \\
\hline \multirow{2}{*}{$\ln \left(y_{t-1} / p_{0} p_{t-1}\right)$} & -.046 & .0046 & -.066 \\
\hline & $(-.44)$ & $(.02)$ & $(-1.38)$ \\
\hline \multirow[t]{2}{*}{ dereg $_{t-1}$} & -.013 & -.015 & $-.019+$ \\
\hline & $(-1.03)$ & $(-.77)$ & $(-1.90)$ \\
\hline \multirow[t]{2}{*}{$\ln \left(\right.$ assetrate $\left._{t-1}\right)$} & $-.20 * *$ & -.093 & -.0045 \\
\hline & $(-3.62)$ & $(-1.17)$ & $(-.11)$ \\
\hline \multirow[t]{2}{*}{$\ln \left(h h i_{t-1}\right)$} & .0031 & -.029 & $.18^{* *}$ \\
\hline & $(.02)$ & $(-1.09)$ & (7.73) \\
\hline \multirow{2}{*}{ In $_{\left.\text {inmigration }_{t-1}\right)}$} & $.028+$ & $.043+$ & $.034+$ \\
\hline & $(1.65)$ & $(1.91)$ & $(1.76)$ \\
\hline \multirow{2}{*}{$\ln \left(\right.$ congest $\left._{t-1}\right)$} & & -.020 & \\
\hline & & $(-.88)$ & \\
\hline $\mathrm{R}^{2}$ (within) & .38 & .48 & .19 \\
\hline No. of observations & 5,079 & 1,386 & 29,835 \\
\hline No. of markets & 318 & 87 & 1,897 \\
\hline
\end{tabular}

Note: All regressions include market and year fixed effects and account for correlated errors within markets. t-statistics are reported in parentheses, and the symbols,$+ *$, and $* *$ denote statistical significance at the 10,5 , and 1 percent levels, respectively. 